\title{
Neurocognitive Assessment of Ecuadorian Andean Children Living at High Altitude in the Cotopaxi Mountain Region
}

\author{
$S$ Allen Counter, DMSc, $P h D^{1,2}$, Leo H Buchanan, $P h D^{3}$, Fernando Ortega, MD, MA, PhD ${ }^{4 *}$, Anthony $B$ \\ Jacobs $^{5}$ and Göran Laurell ${ }^{6}$
}

${ }^{1}$ Department of Neurology, Harvard Medical School/The Biological Laboratories, Cambridge, Massachusetts, USA

${ }^{2}$ Department of Neurophysiology, Massachusetts General Hospital, Boston, Massachusetts, USA

${ }^{3}$ Department of Otolaryngology, Audiology Clinic, Harvard University Health Services, Cambridge, Massachusetts, USA

${ }^{4}$ College of Health Sciences, School of Public Health and Galapagos Institute of Arts and Sciences GAIAS, Universidad San

Francisco de Quito, Quito, Ecuador

${ }^{5}$ Harvard Biological Laboratories, Cambridge, Massachusetts USA

${ }^{6}$ Department of Surgical Sciences, Uppsala University, Uppsala, Sweden

\begin{abstract}
Previous studies have reported neurocognitive deficits in persons living at high altitudes. This study was conducted to assess the neurocognitive performance of children who have resided their entire lives at altitudes of 3500 to 4200 meters in the Ecuadorian Andes. Neurocognitive performance was assessed with the Raven Coloured Progressive Matrices (RCPM) and the Digit Span (DS), tests which are reported to have minimal cultural bias. RCPM results were calculated for the Ecuadorian children for four different RCPM standardized test norms. For the British norms, a mean standard score of 2.9 (SD: 1.6; median: 2.4) was calculated, and for the United States norms, the mean standard score was 2.9 (SD: 1.8; median: 2.8), which was not significantly different from the British norms $(p=0.628)$. Using the Puerto Rico norms for analysis, the mean standard score was 4.4 (SD: 1.9; median: 3.6), and for the Peru norms, the mean standard score was 4.9 (SD: 2.1; median: 5.0). The standard scores calculated using the Puerto Rican and Peru norms were significantly higher than those for the British $(p=<0.0001)$ and the United States $(p=<0.0001)$ norms. The difference between the Puerto Rican and the Peru norms was also statistically significant $(p=0.005)$, with the Peru norms yielding a slightly higher score for the Ecuadorian children. The mean DS Forward score was 6.8 (SD: 1.6; median: 6.5, and the mean DS Backward score was 5.1 (SD: 1.6; median: 5.0). The DS Forward score was significantly higher than the DS Backward score $(p=<0.0001)$. The mean DS scale score of 7.0 was less than the average scale score of 10 for the DS. The mean percent $\mathrm{SaO}_{2}$ was 91.5 $(S D=4.0$; range $=77-96$; median $=92)$ and the mean heart rate was $81.6 \mathrm{bpm}(\mathrm{SD}=17.0$; range $=58-125 ;$ median $=77)$. In conclusion, these results overall indicate that the Ecuadorian children who reside at high altitudes show less than average neurocognitive performance. It is unclear whether their poor neurocognitive performance is related altitude or to other variables, such as: Possible cultural differences, malnutrition, poverty and extreme poverty which are widespread in the community.
\end{abstract}

Keywords

Andean, Neurocognitive, Neuropsychological, Hypoxia

\section{Introduction}

A number of studies have reported neurocognitive deficits in adults and children living at high altitudes ( $>2500$ meters) [1-6]. Using a variety of neuropsychological metrics, these investigations found that high altitude dwellers or individuals exposed to hypobaric hypoxic conditions exhibited impairment in neurocognitive performance that included, depending on the study, deficits in executive function, verbal fluency, memory, sustained attention, and processing speed compared to persons residing at lower altitudes. Other studies, however, have found no marked effects of high altitude
*Corresponding author: Fernando Ortega MD, MA, PhD, School of Public Health, College of Health Sciences, Universidad San Francisco de Quito, Diego de Robles y Pampite, Cumbaya, Quito, Ecuador, Tel: (593)-9-9850-2526, Fax: (593-2)-289-0070

Accepted: July 15, 2019

Published online: July 17, 2019

Citation: Counter SA, Buchanan LH, Ortega F, et al. (2019) Neurocognitive Assessment of Ecuadorian Andean Children Living at High Altitude in the Cotopaxi Mountain Region. J Soil Water Sci 3(1):84-90 
Citation: Counter SA, Buchanan LH, Ortega F, et al. (2019) Neurocognitive Assessment of Ecuadorian Andean Children Living at High Altitude in the Cotopaxi Mountain Region. J Soil Water Sci 3(1):84-90

on physical development or neurocognitive functioning [7-9].

Rimoldi, et al. $[5,6]$ reported that high altitude neuropsychological impairment in children was more severe than that reported in adults and suggested that children may be more sensitive than adults to altitude-induced neuropsychological damage, concluding that deficits are more severe in children that are permanently living at high altitude and could harm their learning abilities. Virues-Ortega, et al. [10] in a study of Bolivian children born and residing at 3700-4100 meters speculated that the children's impaired neurocognitive functioning may be related to loss of cerebral blood flow autoregulation at high altitude.

As part of general medical services to assist the population, and in light of previous studies showing altitude-related neurocognitive deficits, the present study was conducted to assess the neurocognitive performance of children who have resided their entire lives at altitudes of 3500 to 4200 meters. The current study used test instruments with reported minimal cultural bias.

\section{Methods and Materials}

\section{Participants and locations}

The participants in this study live at elevations of 35004200 meters in the Guangaje parish villages of Curingue and Tingo Pucará. This primarily sheep herding population lives and conducts daily activities at the afore mentioned altitudes in the west ranges of the Andes in Cotopaxi Province, Ecuador. Previous medical examinations by one of the authors (FO) of children and adults in the mentioned communities have shown widespread malnutrition.

Chronic malnutrition among children is an important public health problem in Ecuador, particularly among indigenous populations living in rural highlands with strong socioeconomic disparities such as: Lack of health care facilities, roads, potable water, and sewage. The National Health and Nutrition Survey published in 2014 showed $25.3 \%$ of chronic malnutrition prevalence among children under 5 years of age, prevalence rate which among rural indigenous children rises to $42.3 \%$. The indigenous communities evaluated in this study have considerably higher rates than the national average [11].

Regarding their socio-economic status, inequality and poverty, Tingo Pucara and Curingue communities, were characterized based on the 2010 Population and Housing Census. "The parish of Guangaje is $91.1 \%$ extremely poor for unsatisfied basic needs (NBI). Analyzed by sex, the prevalence of extreme poverty corresponds $91.3 \%$ to women while $90.8 \%$ to men. Poverty prevalence rates for unsatisfied basic needs are 99.9\%" [12].

For the current study, the children were screened for neurocognitive status as part of a comprehensive medical evaluation. Thirty-one children (19 females and 12 males), aged 7.0-11.5 years (mean age: 9.1; SD: 1.5; median age: 9.0 years) were administered the Raven Coloured Progressive Matrices (RCPM), and 33 children ( 21 females and 11 males) aged 7.0-15.1 years (mean age: 10.3; SD: 2.4; median age:
10.1 years) were given the Digit Span (DS). The children are of indigenous background and have lived all of their lives in high altitude. The thirty-three children from Tingo Pucara and Curingue communities participating in this study represent $80 \%$ of total children population aged 7-15 years. All of them are Spanish speaking children assisting to a Spanish speaking educational institution.

\section{Neurocognitive test instrument: Raven coloured progressive matrices}

Instructions for RCPM were given in Spanish (a common language of the communities) and the test was administered by trained Ecuadorian psychologists according to the guidelines in the test manual $[13,14]$. All testing was conducted in a quiet, isolated, and well-illuminated setting. The RCPM was selected because it is a language-free measure of visual-spatial skills and non-verbal reasoning that correlates with standard tests of intelligence, such as the Wechsler Intelligence Scale for Children [13]. In addition, the RCPM is reported to have minimal cultural bias, and to be a sensitive tool for evaluating the intellectual status of children. The RCPM is an untimed test with items that increase in complexity as the test progresses. Initially each test page of the RCPM displays a single colored pattern with a missing piece, and a choice of 6 pieces from which the one that completes the pattern is to be chosen. Later items involve the presentation of discrete elements that form visual-spatial and logical patterns, and correct choices must be based on inferences drawn from these patterns. Normative data have been obtained for RCPM performance by children in a number of countries, including Spanish-speaking nations, such as Argentina and Peru, as well as the U.S. Commonwealth of Puerto Rico. Since there are no Ecuadorian norms for the RCPM, we used the standardized Peru and Puerto Rico norms to minimize possible cultural and linguistic bias. For comparison purposes, the standardized British and United States norms were used in data analysis to illustrate how culturally inappropriate norms may influence the results. The United States norms were used because they have detailed percentile scores and a wider age range $[15,16]$.

\section{Neurocognitive test instrument: Digit span (DS)}

The DS subtest of the Spanish version of the Wechsler IV Intelligence Scale for children [17] was used to assess auditory (verbal) memory in the children of the study group. The DS is standardized for children aged 6 years to 16 years- 11 months. The DS is a test of short-term auditory memory (DS Forward score) and working memory (DS Backward score) in which a series of two to nine digits are presented verbally to the participant, who then must repeat the numbers in forward, then reverse order during different parts of the test. While the DS Forward is essentially a test of short-term, rote memory, the DS Backward is a test of working memory in which the participant must transform and manipulate verbal information while it is in temporary memory storage $[9,18]$. Similar to the RCPM, the DS appears to have a low susceptibility to cultural bias, and the DS requires adequate hearing acuity, vigilant listening, and concentration, and has been used as a test of attention, as well as a measure of auditory memory $[18,19]$. Hearing disorders were ruled out in each of the children by 
audiologic measures that included otoscopic examination and tympanometry to examine the ear canal and middle ear system, and by pure-tone threshold determination to assess the integrity of the conductive and sensory-neural hearing apparatus. The instructions and the digits themselves were presented in Spanish by trained Ecuadorian psychologists in a well-lighted and quiet setting.

\section{Oxygen saturation and heart rate}

Pulse oximetry was used to measure percent oxygen saturation in the study group. Pulse oximetry, which is a noninvasive procedure, is considered a reliable method for the estimation of arterial oxygen saturation $\left(\mathrm{SaO}_{2}\right)[20,21]$, and in association with heart rate (which was also measured) may be informative regarding acclimatization to altitude [20]. The $\mathrm{SaO}_{2}$ values were compared to the neurocognitive test results for the RCPM and the DS to determine if neurocognitive test performance varied with the level of oxygen saturation.

\section{Statistical Analysis}

For statistical analysis, the means, standard deviations, medians, ranges, and percentiles were calculated for all quantitative variables. Both parametric and nonparametric statistical tests were used to analyze the data. The paired $t$-test was used to assess the differences among the four RCPM test norms. The Pearson correlation coefficient was used to determine if the RCPM test scores correlated with the DS test scores. Because of skewed distributions ( $>2$ standard errors of skewness) for $\mathrm{SaO}_{2}$ and heart rate, Spearman rho correlation coefficient was used to examine the relation between $\mathrm{SaO}_{2}$ and heart rate. Spearman rho analyses also were used to probe for associations among the standard scores for the four RCPM test norms and $\mathrm{SaO}_{2}$, and between the scale score for the DS and $\mathrm{SaO}_{2}$. All $p$-values reported for the Spearman rho correlation coefficient are tied $p$-values. An alpha level of $<0.05$ was accepted as an indication of statistical significance.

\section{Results}

\section{Neurocognitive test results}

Figure 1 compares the performance of the study group on the RCPM for different test norms using RCPM standard scores. For the RCPM, a standard score of 5 is average, or equivalent to an IQ of 100 . For the British norms, the study group obtained a mean standard score of 2.9 (SD: 1.6; range: 1.6-8.3; median: 2.4 ) and for the United States norms, the mean standard score was 2.9 (SD: 1.8; range: 0.6-7.3; medi-

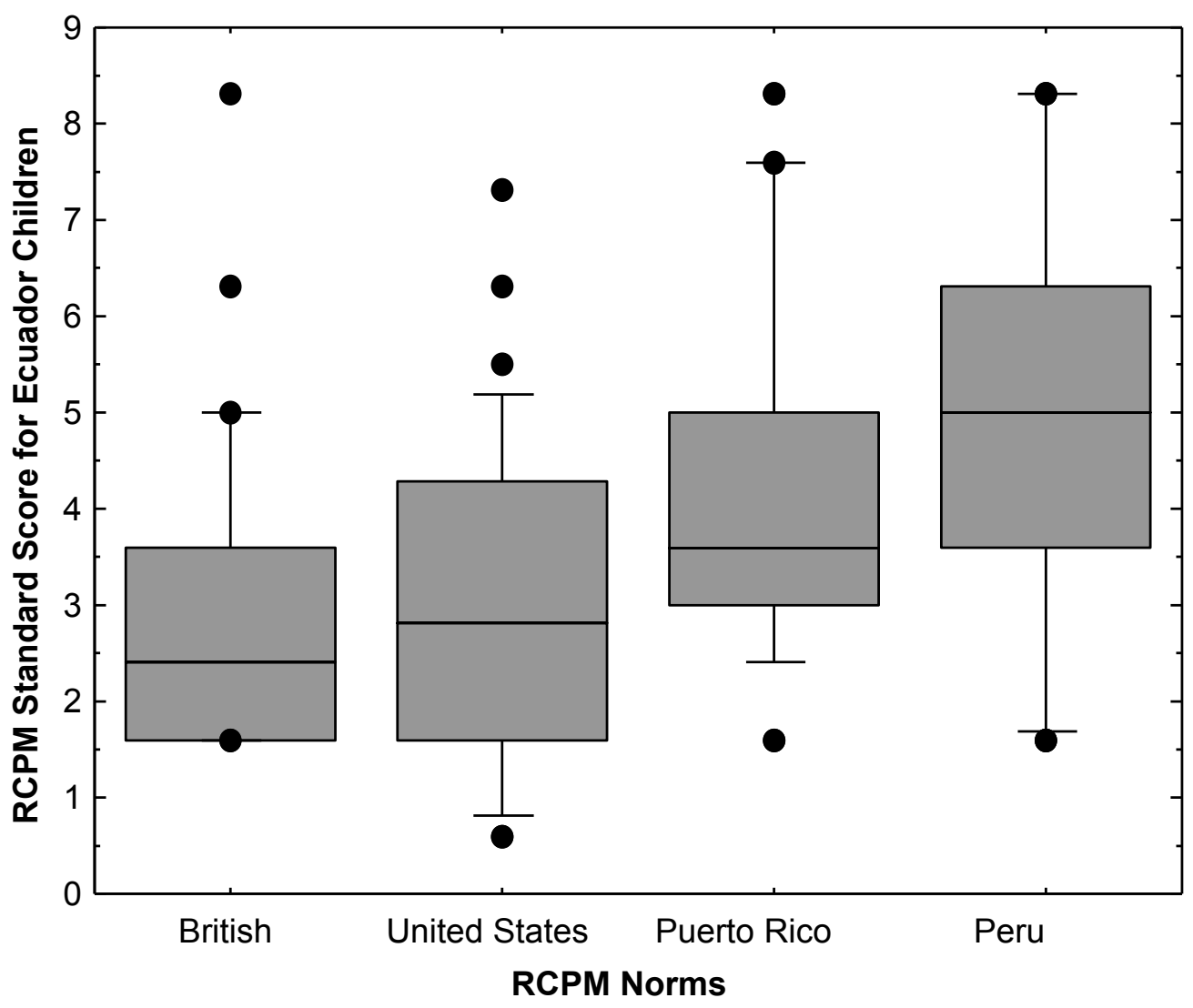

Figure 1: Box plots comparing Raven Coloured Progressive Matrices (RCPM) standard scores for Andean children residing at 3500-4200 meters above sea level in the Cotopaxi Province of Ecuador using different RCPM standards based on norms from children in Britain, the United States, Puerto Rico and Peru. The boxes contain individual scores between the $25^{\text {th }}$ and $75^{\text {th }}$ percentiles. The horizontal lines inside the boxes represent the $50^{\text {th }}$ percentile. The small horizontal lines above the boxes represent the $90^{\text {th }}$ percentile, and the small horizontal lines below the boxes represent the $10^{\text {th }}$ percentile. The individual data points represent cases above the $90^{\text {th }}$ percentile and below the $10^{\text {th }}$ percentile. The results show the dramatic differences in scores depending on the norms used to depict the raw data. 
Citation: Counter SA, Buchanan LH, Ortega F, et al. (2019) Neurocognitive Assessment of Ecuadorian Andean Children Living at High Altitude in the Cotopaxi Mountain Region. J Soil Water Sci 3(1):84-90

an: 2.8). The British and USA standard scores were not significantly different for the Ecuadorian children (paired $t$-test, $p=$ 0.575). Using the Puerto Rican norms for analysis, the mean standard score was 4.4 (SD: 1.9; range: $1.6-8.3$; median: 3.6$)$, and for the Peruvian norms, the mean standard score was 4.9 (SD: 2.1 ; range: $1.6-8.3$; median: 5.0 ) for the Ecuadorian children. The standard scores obtained using the Puerto Rican and Peruvian norms were significantly higher than those obtained using the British ( $p=<0.0001)$ and the United States ( $p$ $=<0.0001$ ) norms for the Ecuadorian children. The difference between the Puerto Rican \& Peru norms was also statistically significant $(p=0.002)$, with the Peru norms yielding a slightly higher score for the Ecuadorian children.

Table 1 lists the percentage of children and their intellectual classifications using the RCPM test standards as a function of four different test norms. Approximately $35 \%$ of the children were classified as Above Average to Superior when the Peru norms were used to categorize the RCPM test results, but only $6.4 \%$ to $17.8 \%$ of the children fell in the Above Average to Superior classification when the British, United States and Puerto Rico norms were used to classify the results. Approximately $27 \%$ of the children were classified as Below Average using the Peruvian norms, whereas, about $39 \%$ to $48 \%$ were classified as Below Average using the British, United States and Puerto Rico norms. A relatively small percentage of the children were categorized as have an intellectual disability for the Puerto Rican (7.1\%) and the Peruvian (11.5\%) norms compared to the British and United States norms.

Figure 2 shows DS Forward and DS Backward results for the study group. The mean DS Forward score was 6.8 (SD: 1.6; range: 4.0-11.0; median: 6.5, and the mean DS Backward

Table 1: Percentage of Ecuadorian children residing at 3500-4200 meters above sea level in the Andes Mountains with specified intellectual classifications according to different test norms on the Raven Coloured Progressive Matrices (RCPM).

\begin{tabular}{|l|l|l|l|l|}
\hline RCPM Norms & British & United States & Puerto Rico & Peru \\
\hline Intellectual Classification & 3.2 & 0 & 7.1 & 15.4 \\
\hline Superior & 3.2 & 6.5 & 10.7 & 19.2 \\
\hline Above Average & 9.7 & 25.8 & 28.6 & 26.9 \\
\hline Average & 48.4 & 38.7 & 46.4 & 26.9 \\
\hline Below Average & 35.5 & 29 & 7.1 & 11.5 \\
\hline Intellectual Disability & & & \\
\hline
\end{tabular}

The Puerto Rico and Peru columns do not total $100 \%$ because of rounding. The scores were normalized to create the percentages represented in this table.

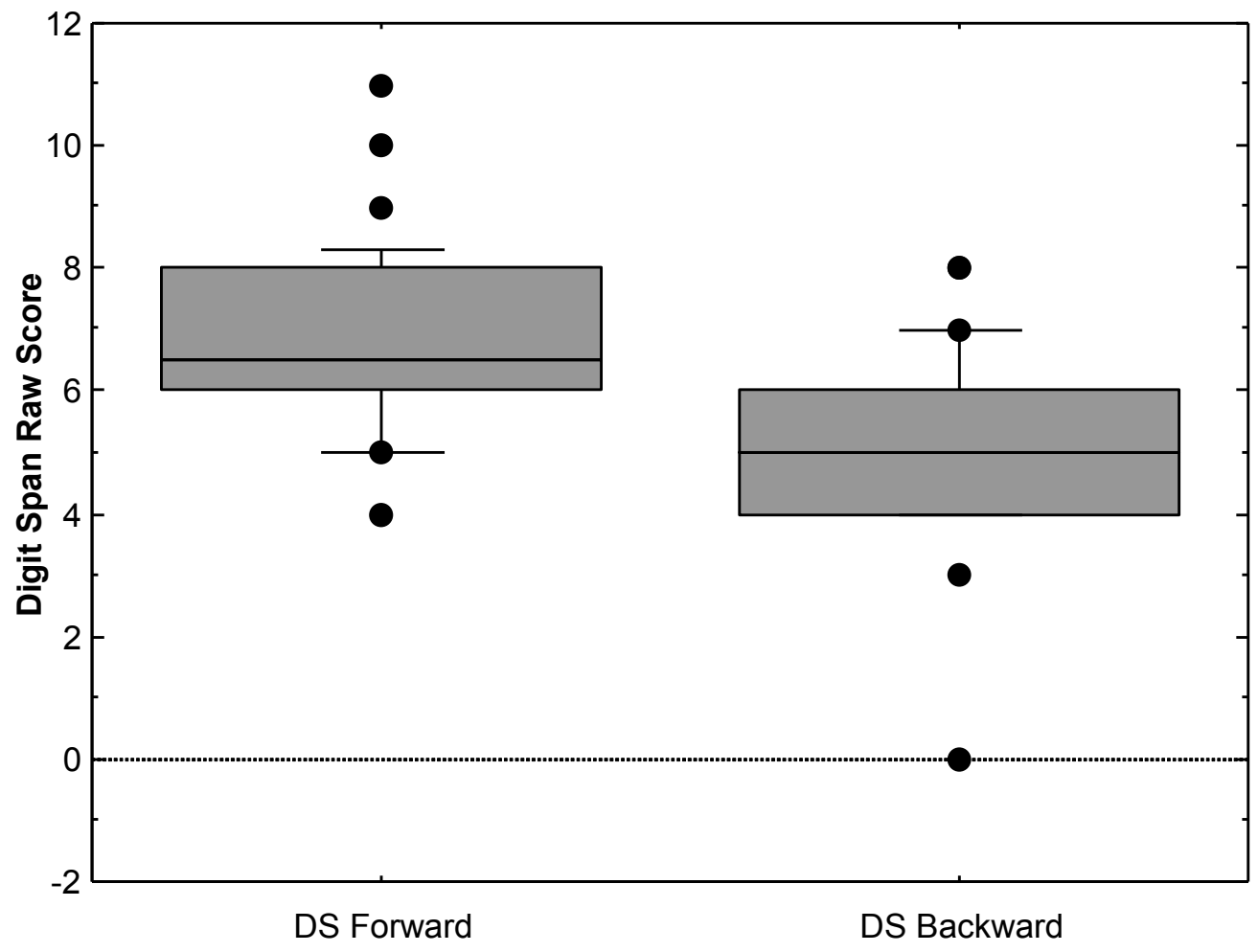

Figure 2: Box plots of raw scores for Digit Span Forward and Digit Span Backward for Ecuadorian Andean children residing at 3500 to 4200 meters. 

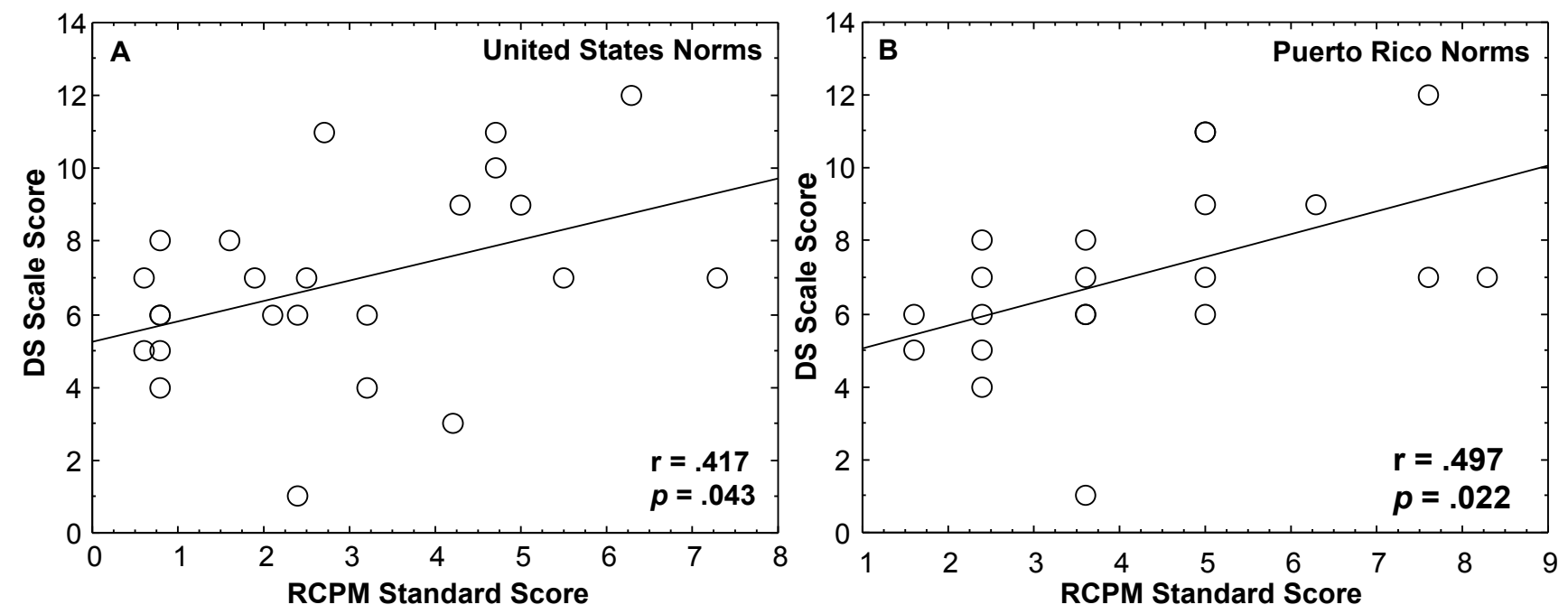

Figure 3: Correlation of Raven Coloured Progressive Matrices (RCPM) standard scores for the United States norms A) and the Puerto Rico norms; B) with the Digit Span scale scores for Ecuadorian Andean children residing at 3500 to 4200 meters.

score was 5.1 (SD: 1.6; range: 0-8.0; median: 5.0). The DS Forward score was significantly higher than the DS Backward score (paired $t$-test, $p=<0.0001$ ), indicating that the children were able to remember and repeat more digits in a forward manner than in a backward manner. Converting the raw DS Forward and Backward scores to scale scores yielded a mean DS scale score or 7.0, which is less than the average scale score of 10 for the DS.

Figure 3 shows the association of the RCPM test of visualspatial intelligence with the DS test of auditory memory. Using the United States RCPM norms (A) to analyze the results for the Ecuadorian children revealed a significant association between the RCPM standard score and the DS test of auditory memory/attention $(r=0.417, p=0.043)$. The Puerto Rico RCPM norms (B) also showed a significant correlation between the RCPM standard score and the DS scale score ( $r$ $=0.497, p=0.022$ ). The British norms showed a correlation of 0.249 , but this did not reach statistical significance $(p=$ 0.201 ). The Peru norms revealed a correlation of 0.183 , but this also did was not statistically significant ( $p=0.427)$.

\section{Oxygen saturation and heart rate results}

The mean percent $\mathrm{SaO}_{2}$ was 91.5 (SD = 4.0; range = 77-96; median $=92$ ) and the mean heart rate was $81.6 \mathrm{bpm}(\mathrm{SD}=$ 17.0; range $=58-125 ;$ median $=77$ ). Because the $\mathrm{SaO}_{2}$ and heart rate data were skewed, the Spearman rho correlation coefficient was used to probe for an association between these two variables. The correlation analysis revealed a significant negative association between the $\mathrm{SaO}_{2}$ level and heart rate ( $r h o=-0.359, p=0.049$ ), indicating that as the $\mathrm{SaO}_{2}$ level decreased, the heart rate increased. Correlation analyses revealed no significant associations of $\mathrm{SaO}_{2}$ with the RCPM standard scores calculated for the Ecuadorian children in this study for any of the four RCPM norms (United States, British, Puerto Rico and Peru) analyzed in the current study. The DS scale score also showed no significant association with $\mathrm{SaO}_{2}$ levels.

\section{Nutritional evaluation}

As part of a complete nutritional evaluation component, all children $(n=33)$ followed an anthropometrical measurement. We used a SECA stable stadiometer for mobile length measurement. Based on the Z scores for chronic undernourishment estimation (height for age), established by the World Health Organization [22], $35 \%$ of boys and $45 \%$ of girls resulted under $-2 \mathrm{Z}$ scores. The best nourished one male and two female children reached between 25 and 49 percentiles in height for age evaluation.

\section{Discussion}

As part of general medical examinations, the current study was conducted to assess the neurocognitive performance of children who are native high-altitude residents, and thus have chronic exposure to hypobaric hypoxia, which has been implicated in cognitive impairment $[9,23,24]$. In an attempt to guard against cultural bias, the present study used two tests (the RCPM and the DS) that have been reported to have low susceptibility to cultural bias to assess neurocognitive performance in children residing at 3500 to 4200 meters in the Andes Mountains of Ecuador. The children in this study were of indigenous background, of low and extremely low socioeconomic status, and live in somewhat isolated communities, under not satisfied basic needs conditions, there for we acknowledge possible cultural differences. To determine how much of an effect different RCPM norms would have on the test results for the Ecuadorian children residing in these communities, four different standardized RCPM norms were used to analyze the RCPM results. As shown in Table 1, the different norms had a substantial effect on the percentage of children who were classified as having below average neurocognitive performance, probably illustrating language and socio-cultural differences. The fact that the Ecuadorian children performed less well on the Puerto Rico norms than on the Peru norms, suggests that the difference observed is not just a linguistic or language effect, but may indicate a socio-cultur- 
Citation: Counter SA, Buchanan LH, Ortega F, et al. (2019) Neurocognitive Assessment of Ecuadorian Andean Children Living at High Altitude in the Cotopaxi Mountain Region. J Soil Water Sci 3(1):84-90

al influence. The Puerto Rico RCPM norms were established on an urban population, whereas the RCPM Peru norms were established on Peruvian children from a rural, isolated highland population, like the Ecuadorian children assessed in the current study.

Socio-cultural or language factors do not appear to account for all of the results obtained in the current study. There are indications that on average the Ecuadorian children residing at these high Andean altitudes have some specific neurocognitive deficits. There are currently no standardized Ecuador norms for the RCPM, but the Peru norms may be appropriate for an estimate of neurocognitive functioning for this particular Ecuadorian population since the Peru norms were established on children who lived in a rural and isolated mountain area of Peru [13-15]. Using the RCPM Peru norms as a guide, overall approximately $38 \%$ of the children performed below average on the RCPM test of visual-spatial reasoning. Seventy-eight percent performed below average on the DS test of memory/attention, indicating that a substantial percentage of these high-altitude children had neurocognitive challenges that may impede their academic learning. Judging from the DS test results, short-term and working memory or attention tasks appear to be quite challenging for most of the children. In a previous study concerned with the effects of lead poisoning on neurocognitive performance, the authors found a significant correlation between the test results for the RCPM and DS [16]. The current study also showed significant associations between the RCPM and the DS (see Figure 3). The significant association of the RCPM and the DS suggests that the two tests to some extent tap into the same neurocognitive domain. It has been suggested that the DS Backward task is more of a right hemisphere task that uses visual-spatial strategies $[25,26]$.

The findings of the present study may be consistent with some earlier studies in showing that children living at high altitudes for their entire lives exhibit below average performance on some neurocognitive tasks. In the current study, the children exhibited below average neurocognitive performance in non-verbal visual-spatial reasoning and shortterm and working memory. The observed neurocognitive deficits may be related to chronic hypobaric hypoxia from continuous exposure to a low oxygen environment, even among people who have resided in these high-altitude enclaves for generations and are presumably adapted or acclimatized to higher elevations. The mean $\mathrm{SaO}_{2}$ level in the present study of 91.5 was higher than $\mathrm{SaO}_{2}$ of 85.7 found in a previous similarly high altitude study (4300 meters) of children aged 5-16 years [21], but similar to the $\mathrm{SaO}_{2}$ level of 91.3 found in children aged 6-18 years of Quechua ancestry living at an altitude of $\mathbf{4 1 0 0}$ meters in the rural community of Nuñoa in the Southern Peruvian Andes [20]. The results also are comparable to the $90.9 \mathrm{SaO}_{2}$ and the $90.3 \mathrm{SaO}_{2}$ levels obtained on Tibetan children and adolescents (aged 10-19 years) living at 3800 and 4065 meters, respectively [27]. The relatively high mean $\mathrm{SaO}_{2}$ level and the decrease in heart rate as $\mathrm{SaO}_{2}$ increased found in the current study may suggest adaptation to high altitude hypoxia [20] by these native highaltitude Andean residents.
Although the high-altitude Ecuadorian children manifested reduced neurocognitive performance, it is not clear from the current study if the neurocognitive impairments are related to altitude. There was no significant correlation of neurocognitive test performance with $\mathrm{SaO}_{2}$ levels, which is not unreasonable to expect if neurocognitive performance is related to altitude. The association of hypobaric hypoxia or hypoxic stress and cognitive impairment from living at high altitudes is a controversial concept [28]. West [28] has suggested that the best way to obtained conclusive evidence that the neuropsychological impairments found in highlanders are related to the low oxygen environment is to obtain neurocognitive measurements on the same participants at different levels of oxygenation. As previously mentioned, socio-cultural and socioeconomic conditions may be confounding variables affecting neurocognitive test performance in individuals residing at high altitudes. Malnutrition as established in the nutritional component, also may be a confounding variable. Malnutrition has been associated with adverse cognitive effects [29-31], and previous medical examinations of children and adults in the current study from the Curingue and Tingo Pucará communities have shown widespread malnutrition. A 99.9\% poverty level, scarce food accessibility, monotonous and inadequate diet quality may be other confounding variables. No correlation effect done in this study and neurocognitive tests [32-35].

In conclusion, the results of this study show that the sample of Andean children living at high altitudes tested in the Curingue and Tingo Pucará communities performed below average on the RCPM test of visual-spatial reasoning and on the DS test of memory/attention. These test instruments were selected because they are reported to have minimal cultural bias. However, several confounding factors may be associated with these findings, including malnutrition, which is widespread among the indigenous children and adults who have inhabited this high-altitude geographical area since birth. Because of the aforementioned confounding variables, it is difficult to conclude that cognitive deficits in children living at high altitude are due to a low oxygen milieu. A larger sample of high-altitude dwellers is required to substantiate this hypothesis. In addition, the high-altitude group should be compared to a reference group of children of similar sociocultural, socioeconomic and nutritional status who reside at a lower altitude before definitive conclusions can be drawn.

\section{Acknowledgements}

In memory of Dr. S Allen Countert and Dr. Leo $\mathrm{H}$ Buchanant my brothers in science, who benefited mankind with their interest and commitment to understand how human populations result affected by lead and mercury contamination, particularly the people from La Victoria, EI Tejar and Racar villages in Ecuadorian territory.

The authors are grateful to Universidad San Francisco de Quito, College of Health Sciences, School of Public Health in Quito, Ecuador for continued support of this collaborative project. We thank Dr. Gonzalo Mantilla, Dean of the College of Health Sciences, Universidad San Francisco de Quito, for ongoing support and advice. The authors thank the David Rockefeller Center for Latin American Studies at Harvard 
Citation: Counter SA, Buchanan LH, Ortega F, et al. (2019) Neurocognitive Assessment of Ecuadorian Andean Children Living at High Altitude in the Cotopaxi Mountain Region. J Soil Water Sci 3(1):84-90

University and its Director, Dr. Brian D. Farrell for support of this project. We thank Dr. Jeremy Bloxham, Dean of Science at Harvard University; Harvard Biological Laboratories; and Harvard University Health Services for support. We also thank Juan David Cevallos and Juan Andrés Pérez Ecuadorian psychologists and the people of Guangaje.

\section{Author Disclosure Statement}

The authors declare no conflict of interest.

\section{References}

1. Yan X, Zhang J, Gong Q, et al. (2011) Prolonged high-altitude residence impacts verbal working memory: An fMRI study. Exp Brain Res 208: 437-445.

2. Asmaro D, Mayall J, Ferguson S (2013) Cognition at altitude: Impairment in executive and memory processes under hypoxic conditions. Aviat Space Environ Med 84: 1159-1165.

3. Hill CM, Dimitriou D, Baya A, et al. (2014) Cognitive performance in high-altitude Andean residents compared with low-altitude populations: From childhood to older age. Neuropsychology 28 : 752-760.

4. Davis JE, Wagner DR, Garvin N, et al. (2015) Cognitive and psychomotor responses to high-altitude exposure in sea level and high-altitude residents of Ecuador. J Physiol Anthropol 34: 2.

5. Niermeyer S, Mollined PA, Huicho L (2009) Child health and living at high altitude. Arch Dis Child 94: 806-811.

6. Yan $X$ (2014) Cognitive impairments at high altitudes and adaptation. High Alt Med Biol 15: 141-145.

7. Pavlicek V, Schirlo C, Nebel A, et al. (2005) Cognitive and emotional processing at high altitude. Aviat Space Environ Med 76: 28-33.

8. Richardson C, Hogan AM, Bucks RS, et al. (2011) Neurophysiological evidence for cognitive and brain functional adaptation in adolescents living at high altitude. Clin Neurophysiol 122: 1726-1734.

9. Malle C, Ginon B, Bourrilhon C (2016) Brief working memory and physiological monitoring during a high-altitude expedition. High Alt Med Biol 17: 359-364.

10. Virués-Ortega J, Bucks R, Kirkham FJ, et al. (2011) Changing patterns of neuropsychological functioning in children living at high altitude above and below $4000 \mathrm{~m}$ : A report from the Bolivian children living at altitude (BoCLA) study. Dev Sci 14: 1185-1193.

11. Freire WB, Ramírez-Luzuriaga MJ, Belmont P, et al. (2014) Tomo I: Encuesta Nacional de Salud y Nutrición ENSANUT ECU 2012.

12. Guangaje GAD (2015) Actualización del plan de desarrollo y ordenamiento territorial de la parroquia rural de Guangaje.

13. Raven J, Raven JC, Court JH (1998) Manual for raven's progressive matrices and vocabulary scales: Section 2 coloured progressive matrices. Oxford Psychologists Press Ltd, London.

14. Raven J (2000) Manual for raven's progressive matrices and vocabulary scales. Oxford Psychologists Press Ltd, London.

15. Counter SA, Buchanan LH, Ortega F (2006) Neurocognitive screening of mercury-exposed children of andean gold miners. Int J Occup Environ Health 12: 209-214.

16. Counter SA, Buchanan LH, Ortega F (2009) Neurocognitive screening of lead-exposed Andean adolescents and young adults. J Toxicol Environ Health A 72: 625-632.

17. (2005) Escala de Inteligencia de Wechsler para Niños-IV (WISCIV). Harcourt Assessment, Inc, Madrid, Spain.

18. Hale JB, Hoeppner JB, Fiorello CA (2002) Analyzing digit span components for assessment of attention processes. J Psychoeduc Assess 20: 128-143.

19. Ballester-Plané J, Laporta-Hoyos O, Macaya A, et al. (2016) Measuring intellectual ability in cerebral palsy: The comparison of three tests and their neuroimaging correlates. Res Dev Disabil 56: 83-98.

20. Huicho L, Pawson IG, León-Velarde F, et al. (2001) Oxygen saturation and heart rate in healthy school children and adolescents living at high altitude. Am J Hum Biol 13: 761-770.

21. Schult S, Canelo-Aybar C (2011) Oxygen saturation in healthy children aged 5 to 16 years residing in Huayllay, Peru at $4340 \mathrm{~m}$. High Alt Med Biol 12: 89-92.

22. World Health Organization (2014) Child growth standards.

23. Hogan AM, Virues-Ortega J, Botti AB, et al. (2010) Development of aptitude at altitude. Dev Sci 13: 533-544.

24. Muthuraju S, Pati S (2014) Effect of hypobaric hypoxia on cognitive functions and potential therapeutic agents. Malays J Med Sci 21: 41-45.

25. Rapport L, Webster JS, Dutra RL (1994) Digit span performance and unilateral neglect. Neuropsychologia 32: 517-525.

26. Hoshi Y, Oda I, Wada Y, et al. (2000) Visuospatial imagery is a fruitful strategy for the digit span backward task: A study with near-infrared optical tomography. Cogn Brain Res 9: 339-342.

27. Beall CM (2000) Oxygen saturation increases during childhood and decreases during adulthood among high altitude native Tibetans residing at 3,800-4,200 m. High Alt Med Biol 1: 25-32.

28. West JB (2016) Barcroft's bold assertion: All dwellers at high altitudes are persons of impaired physical and mental powers. J Physiol 594: 1127-1134.

29. Kar BR, Rao SL, Chandramouli BA (2008) Cognitive development in children with chronic protein energy malnutrition. Behav Brain Funct 4: 31.

30. Crookston BT, Dearden KA, Alder SC, et al. (2011) Impact of early and concurrent stunting on cognition. Matern Child Nutr 7: 397409.

31. Venables PH, Raine A (2016) The impact of malnutrition on intelligence at 3 and 11 years of age: The mediating role of temperament. Dev Psychol 52: 205-220.

32. Ortega $F(2017)$ Estado nutricional de los niños de Curingue y Tingo Pucara, parroquia de Guangaje. Cotopaxi, Ecuador.

33. Counter SA, Buchanan LH, Ortega F (2013) Brainstem auditory evoked responses in children living at high altitude in the andes mountains. High Alt Med Biol 14: 155-161.

34. Counter SA, Buchanan LH, Ortega F, et al. (2017) Assessment of the brainstem-mediated stapedius muscle reflex in Andean children living at high altitudes. High Alt Med Biol 18: 37-45.

35. Pollard AJ, Niermeyer S, Barry P, et al. (2001) Children at high altitude: An international consensus statement by an ad hoc committee of the International Society for Mountain Medicine, March 12, 2001. High Alt Med Biol 2: 389-403.

DOI: $10.36959 / 624 / 433$

Copyright: (C) 2019 Counter SA, et al. This is an open-access article distributed under the terms of the Creative Commons Attribution License, which permits unrestricted use, distribution, and reproduction in any medium, provided the original author and source are credited. 